\title{
Wear of NiTi coatings obtained by thermal spraying
}

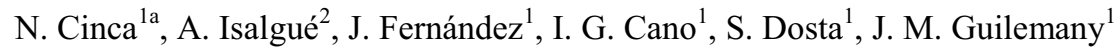 \\ ${ }^{1}$ Dep. Materials Science and Metallurgical Engineering, University of Barcelona, Diagonal 649, E-08028 \\ ${ }^{2}$ Dep. Física Aplicada UPC, Pla Palau 18, Barcelona E-08003 (SPAIN)
}

\begin{abstract}
Shape Memory Alloys are interesting not only for shape memory and pseudo-elastic properties, but also for relevant wear resistance near their transition temperature. NiTi has also high oxidation and corrosion resistance, and these properties together with the wear resistance suggest its use as coating to increase the lifetime of some parts. In this work we expose the results obtained with thermally sprayed coatings of NiTi using vacuum plasma spray (VPS), atmospheric plasma spray (APS) with quenching, and high velocity oxy-fuel spray (HVOF). The wear behaviour has been studied by rubber-wheel equipment and ball-on-disk tests. The results obtained at room temperature show that the APS-quenching coatings exhibit a preferential dry sliding wear mechanism, while the VPS and HVOF coatings show an abrasive mechanism.
\end{abstract}

\section{Introduction}

NiTi shape memory alloys are widely used in many applications such as actuators, due to their shape memory effect (SME) and super-elastic (SE) behaviours. However, the NiTi alloys have poor cold workability [1]. On the other hand, NiTi shows high resistance to wear as well as to cavitation erosion [2-6]. This feature, related to the shape memory effect, has been understood by the capacity of these materials to absorb energy by the martensitic transformation process. The wear resistance depends on the sum of the pseudo-plastic and pseudo-elastic strain limits [7]. Therefore, pseudo-elasticity has been considered the major property referred to wear resistance. This effect refers to the capacity of SMAs to show a recoverable stress induced martensitic transformation depending on the temperature, as well as to the recoverable reorientation of the martensite domains under stress [1,8-10].

NiTi coatings have been investigated, and most studies deal with the magnetron sputtering technique [1, 11-12, 18] and, in the range of thicker coatings, the most used processing method has been Vacuum Plasma Spraying (VPS) [4, 13-19]. Due to the high reactivity of NiTi alloy with oxygen at high temperatures forming oxides, VPS became one of the more exploited techniques. Nevertheless, its extended use has been limited due to the high costs of the process. Apart from the oxidation problem, corrosion resistance needs a good continuity of the coating to obtain a good sealing able to prevent the electrolyte path. Stella [20] examined the erosion properties of vacuum plasma sprayed specimens and, although they did not demonstrate that coatings had shape memory, they assumed that despite porosity and second phases not showing this effect, the pseudo-elasticity of stoichiometric NiTi phase played some role on improving the wear resistance.

We have further explored the feasibility of other techniques to obtain coatings, such as High Velocity Oxy-Fuel Spraying (HVOF) and Atmospheric Plasma Spraying and quenching (APS-quenching) to obtain NiTi coatings [21]. The APS-quenching technique consists on a conventional APS gun with an external liquid $\mathrm{N}_{2}$ cooling system.

In this work, we report on the wear properties of coatings obtained with these alternative techniques.

\footnotetext{
a e-mail: nuria.cinca@ub.edu
}

This is an Open Access article distributed under the terms of the Creative Commons Attribution-Noncommercial License (http://creativecommons.org/licenses/by-nc/3.0/), which permits unrestricted use, distribution, and reproduction in any noncommercial medium, provided the original work is properly cited. 


\section{Experimental}

The coatings have been obtained as described in [21]. At room temperature, in all cases, NiTi beta phase was identified by X-ray diffraction to be the major component [21]. The corrosion resistance of the coatings has been reported on [22]. The table 1 shows some macroscopic mechanical properties of the coatings.

Table 1. Tensile strength, Vickers micro-hardness and elastic modulus for the as-sprayed NiTi powder.

\begin{tabular}{|l|c|c|c|}
\hline & Adherence, $\mathrm{MPa}$ & Vickers micro-hardness, HV200 & Elastic modulus, GPa \\
\hline VPS & $75,3 \pm 5,1$ & $496 \pm 20$ & $105 \pm 8$ \\
\hline APS-quenching & $43,1 \pm 4,2$ & $549 \pm 43$ & $86 \pm 10$ \\
\hline HVOF & $45,4 \pm 2,9$ & $539 \pm 39$ & $91 \pm 10$ \\
\hline
\end{tabular}

The wear resistance has been studied by rubber-wheel equipment (ASTM G65-91) for abrasion, and ball-on-disk test (ASTM G99-90) for friction. The surfaces have been analyzed optically and with a Scanning Electron Microscope JEOL 5510 operated at $20 \mathrm{kV}$ with an EDS for microanalysis.

\section{Results}

The figures 1, 2 and 3 show the tracks of the friction test for the VPS, APS-quenching, and HVOF NiTi coatings respectively, together with micrographs of the WC-Co sliding counter-face. The table 2 shows the comparison of wear rates for the different NiTi coatings.

Table 2. Wear rates comparison for the different NiTi coatings.

\begin{tabular}{|c|c|c|c|c|}
\cline { 2 - 5 } \multicolumn{1}{c|}{} & \multicolumn{3}{c|}{ Abrasion } & \multicolumn{2}{c|}{ Friction } \\
\cline { 2 - 5 } & $\begin{array}{c}\text { Wear rate } \\
\left(\mathrm{mm}^{3} \mathrm{~N}^{-1} \mathrm{~m}^{-1}\right)\end{array}$ & $\begin{array}{c}\text { Friction } \\
\text { Coefficient }\end{array}$ & $\begin{array}{c}\text { Track width } \\
(\mu \mathrm{m})\end{array}$ & Wear rate $\left(\mathrm{mm}^{3} \mathrm{~N}^{-1} \mathrm{~m}^{-1}\right)$ \\
\hline VPS & $1,410^{-4}$ & $0,88_{6}$ & $1118 \pm 20$ & $5,710^{-5}$ \\
\hline APS-quenched & $9,110^{-5}$ & $0,74_{6}$ & $793 \pm 33$ & $1,810^{-5}$ \\
\hline HVOF & $2,210^{-4}$ & $0,81_{0}$ & $1599 \pm 54$ & $4,210^{-4}$ \\
\hline
\end{tabular}




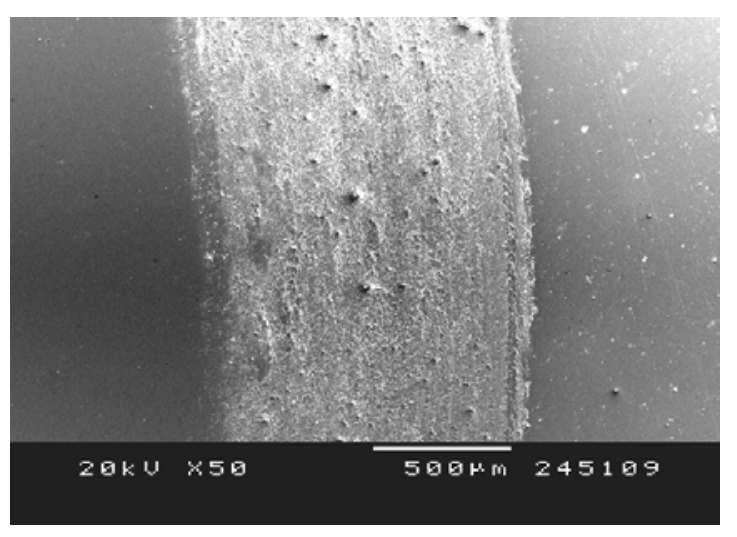

a

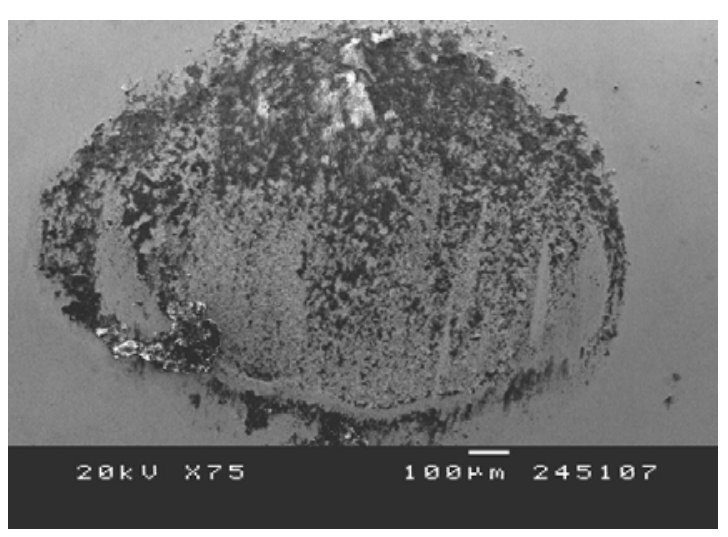

C

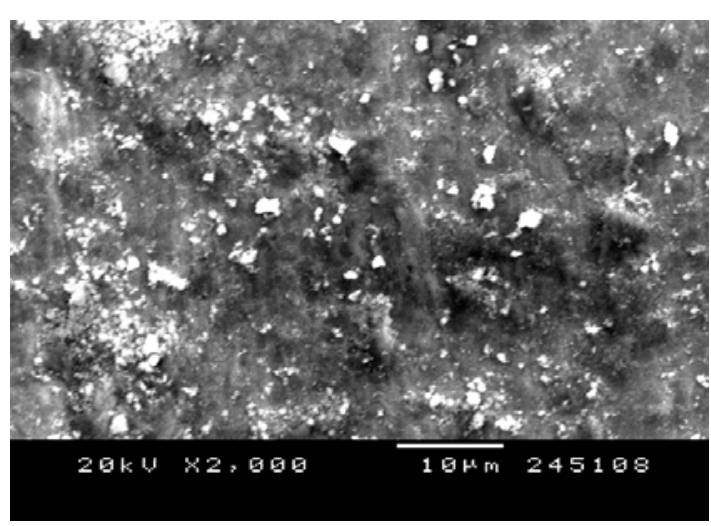

b

Fig. 1. Wear track features of after the sliding test for the VPS NiTi coating (a, b), and micrograph of the ball (c).

By examination of the worn surfaces (figs. 1, 2 and 3), it can be noticed that the APS-quenching is formed by fresh coating and cracking, which made think that the wear mechanism was by fatigue; cracking expansion might be facilitated by continuous cycles of the ball sliding over the coating. By contrast, VPS and HVOF deposits exhibited carbide particles coming from the worn counter-face (WC$\mathrm{Co}$ ). According to this, these particles behave as abrasive between the moving surfaces leading to a more damaging wear effect. In addition, these two coatings also show the largest contact area as seen by ball prints, where it seems that material transference from the sprayed NiTi has taken place. The smallest contact area corresponds to APS $+\mathrm{Q}$ deposit, and this has in turn, the narrowest wear track and the lowest friction coefficient. 


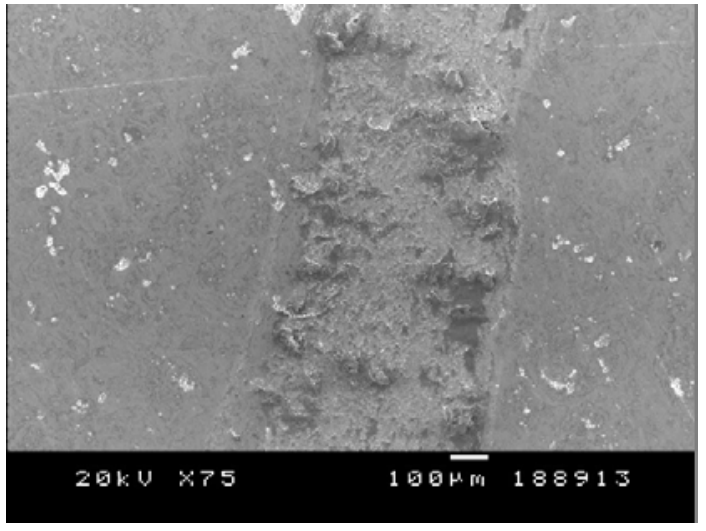

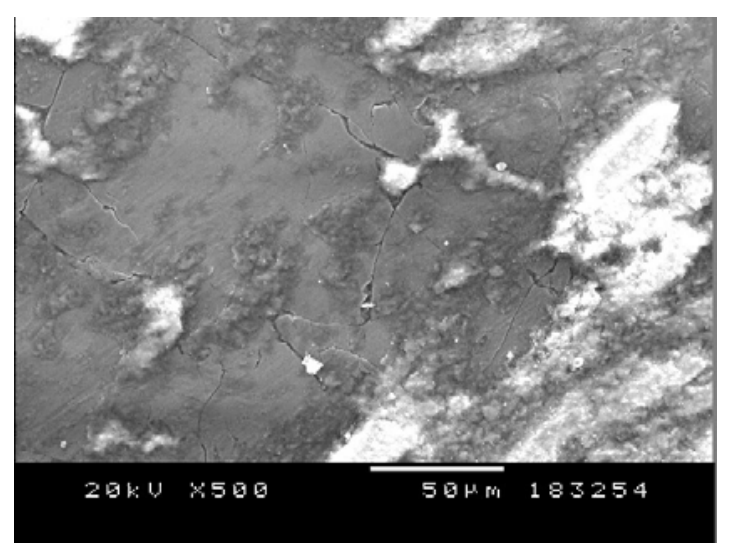

b

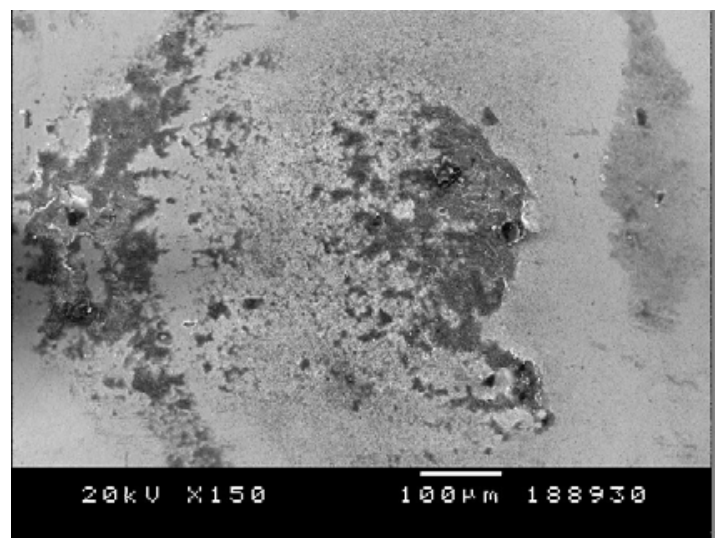

c

Fig. 2. Wear track features of after the sliding test for the APS-quenching NiTi coating $(a, b)$, and micrograph of the ball (c). 


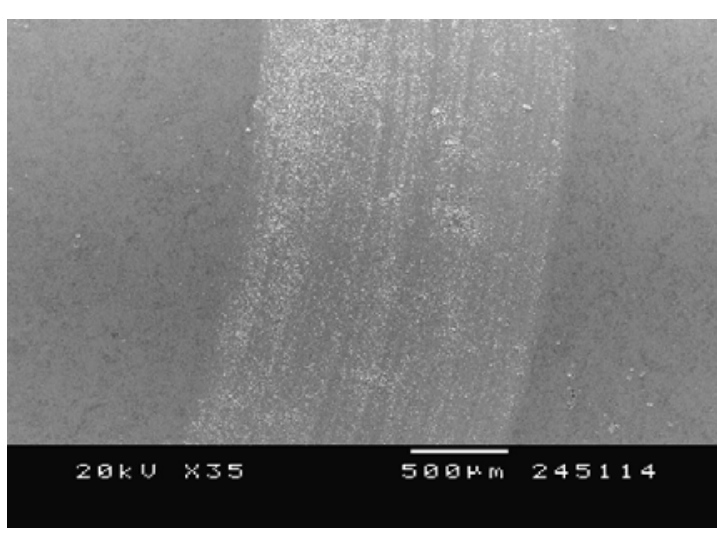

a

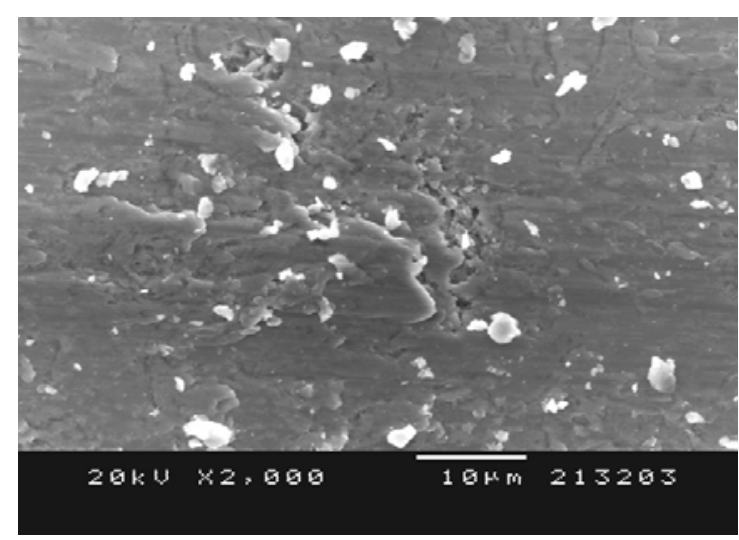

$\mathrm{b}$

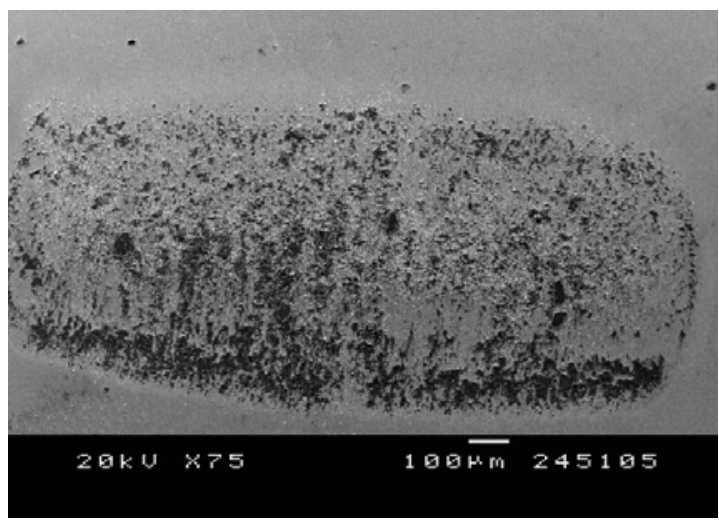

$\mathrm{C}$

Fig. 3. Wear track features of after the sliding test for the HVOF NiTi coating (a, b), and micrograph of the ball (c).

\section{Conclusions}

HVOF and APS-quenching techniques have been evaluated as alternatives to the more expensive VPS procedure for producing NiTi coatings. The results obtained at room temperature show that the APSquenching coatings exhibit a preferential dry sliding wear mechanism, while the VPS and HVOF coatings show an abrasive mechanism. Regarding the three-body abrasion, fairly similar values are obtained and, it is observed a tendency with the material hardness: the hardest deposit (APS-quenching) possesses the lowest wear rate. On the other hand, with regard to the dry sliding behaviour, the highest friction coefficient is that of the VPS coating and the lowest wear rate corresponds to APS-quenching (table 1). By examining the wear tracks, it is concluded that the higher friction coefficient is due to the presence of worn particles entrapped between the two surfaces which behave as abrasive leading to a more damaging wear effect.

\section{Acknowledgements}

The authors are grateful to the Generalitat de Catalunya -project 2005SGR00310- and the Ministerio de Educación y Ciencia for the project MAT2006-06025 regarding the support for the work. N. C. acknowledges the researcher grant with reference number AP-2004-2453. 


\section{References}

[1] K. Otsuka, C.M. Wayman (Eds.), Shape Memory Materials, Cambridge University Press, (1998).

[2] A. Ball, Wear, 91 (1983) pp. 201-207.

[3] Y. Shida, Y. Sugimoto, Wear, 146 (1991) pp. 219-228.

[4] P. Clayton, Wear, 162 (1993) pp. 202-210.

[5] H. C. Lin, S. K. Wu, C. H. Yeh, Wear, 249 (2001) pp. 557-565.

[6] F. T. Cheng, P. Shi, H. C. Man, Mater. Sci. Eng. A, 339 (2003) pp. 312-317.

[7] Y. N. Liang, S. Z. Li, Y. B. Jin, W. Jin, S. Li, Wear, 198 (1996) pp. 236-241.

[8] Otsuka K., Ren X., Progress in Mater. Sci. 50 (2005) 511-678.

[9] http://www.tdcat.cesca.es/TESIS_UPC/AVAILABLE/TDX-0629105-094737//07Sfl07de14.pdf

[10] Itin I., Gyunter V.E., Shabalovskaya S.A., Sachdeva R.L.C., Materials Characterization 32 (1994) 179-187.

[11] Ho K. K., Carman G. P., Thin Solid Films 370, (2000) 18-29.

[12] Yang Y. Q., Jia H. S., Zhang Z. F., Shen H. M., Hu A., Wang Y. N., Materials Letters 22 (1995) 137-140.

[13] Bram M., Ahmad-Khanlou A., Buchkremer H. P., Stöver, Materials Letters 57 (2002) 647-651.

[14] Siegmann S., Halter K., Wielage B. Vacuum plasma sprayed coatings and freestanding parts of Ni-Ti shape memory alloy. ITSC 2003 p 589-595.

[15] Halter K., Sickinger A., Zysset L., Siegmann S., Low Pressure Wire Arc and vacuum Plasma Spraying of NiTi Shape Memory alloys, Thermal Spray 2003: Advancing the Sicence \& Applying the Technology. Ed. C. Moreau and B. Marple. Ohio USA, p. 589-595.

[16] Siegmann S., Halter K., Wielage B. Vacuum plasma sprayed coatings and freestanding parts of nit-it shape memory alloy. ITSC 2002 pp 357-361.

[17] Sickinger A., Thermal Spraying of NiTi alloys, SMST-2003: The International Conference on Shape Memory and Superelastic Technologies; USA; (2004) p. 153-162.

[18] Halter K., Sickinger A., Siegmann S., Zysset L., Thermal Spray forming of NiTi shape memory alloys, SMST-2003: The International Conference on Shape Memory and Superelastic Technologies; USA; (2004) p. 163-172.

[19] Nakayama H, Taya M, Smith RW, et al., Mater. Sci. Eng. A 459 (2007) 52-59.

[20] J. Stella, E. Schüller, C. Heissing, O. A. Hamed, M. Pohl, D. Stöver, Wear 260 (2006) 1020-1027.

[21] N. Cinca, A. Isalgue, J. Fernandez, J.M. Guilemany: NiTi thermal sprayed coatings characterization. Esomat 2009, Prague.

[22] J. M. Guilemany, N. Cinca, S. Dosta, A.V. Benedetti, Corrosion Science 51 (2009) 171-180 . 